\title{
Land Cover Classification using Object-Based Image Analysis of SPOT-6 Imagery for Land Cover and Forest Monitoring in Nagan Raya, Aceh - Indonesia
}

\author{
Inggit L. Sari", Stephen Fildes* \\ ${ }^{\#}$ National Institute of Aeronautics and Space, Jl. Lapan No. 70, Pekayon, Pasar Rebo, Jakarta Timur, 13710, Indonesia, \\ E-mail: inggit.lolita@lapan.go.id \\ *The Flinders University, South Australia
}

\begin{abstract}
Digital classification technique using Object-Based Image Analysis (OBIA) of SPOT-6 imagery could improve classification accuracy and provide detail type of land cover. This method is better applied for data with higher spatial resolution imagery which has high heterogeneity where the pixel size is smaller the actual size of the objects. The sequence steps were image preprocessing and pansharpening, identify the potential of landcover types using Jeffries-Matusita (JM) feature separability, determine a stratification boundary, and developing the Object-Based Orientation classification using Erdas Imagine Objective. Detail process of OBIA was image pixel segmentation with the parameters were consists of determining the minimum pixel segmentation ratio which was 1000 and applying the single feature probability and NDVI, and determine cue weight. The second segmentation was object vector classification which segmented the vector object using the empirical distribution analysis. The segmentation is based on region growing of the Multi-Bayesian network. The classification result is then assessed by comparing the classification result of Maximum Likelihood (MLC) using confusion matrix. The result shows that object-based classification technique could improve the classification by $83 \%$ compared to the MLC with only $67 \%$. The method of segmentation used the stratification zone in order to make an optimum cue weight in detecting the object through texture, size, and shape while also applying the spectral-based method.
\end{abstract}

Keywords — classification; object-based image analysis; SPOT-6

\section{INTRODUCTION}

Forests play an important role in the natural environment. They function as key areas of biodiversity, habitat and natural conservation, water storage, and are vital in carbon sequestration to regulate global climate. The total global forest area in 2015 was estimated to be 3,999Mha and contributes to absorbing $\mathrm{CO}_{2}$ at $2.1 \mathrm{Gt}$, annually during 2011 to 2015 . It has been reported that the total global forested area has declined by $3 \%$ from 4,128Mha in 1990 to $3,999 \mathrm{Mha}$ in 2015 , where the deforestation rate recently reached 3.3Mha per year between 2010 and 2015 [1], [2].

Indonesia has the third largest area of tropical forest after the Amazon and Africa's Congo Basin [3], with a total forested area estimated at $129.4 \mathrm{Mha}$ in 2013. The deforestation rate is estimated at 0.786 Mha per year between 2011 and 2012 [4]. Deforestation is now progressing at an alarming rate in Indonesia, particularly evident in the last few decades.
Attempts to reduce deforestation through building a national forest monitoring system have been implemented by the Government of Indonesia (GOI) since 1989; namely through the National Forest Inventory (NFI) [5]. Currently, the project continues to produce land cover maps using Landsat imagery. The Landsat imagery as one of the remote sensing data that has high continuity, that depict the landcover from its characteristics from spectral, spatial and temporal. The forest monitoring system began to produce the maps in 2000, and they have been updated every three years [6]. The information provides 23 land cover classes, developed using local knowledge from district staff and the visual interpretation of the biophysical appearance of land cover types identified in the satellite imagery. The use of remote sensing technology for mapping at national scale has been widely used because of cost-effective and able to provide a series data. Moreover, it applied in many biogeographical studies such as for producing a land cover map, monitoring, and deriving information about specific habitat and species and supporting biodiversity assessment and conservation [7]. For example, application of remote sensing 
data for mapping land use in the coastal environment was conducted in South Sumatra based on Landsat imagery [8].

The maps from Ministry of Forestry (MoFor) at national scale that provide 23 landcover classes are primary dryland forest, secondary dryland forest, primary mangrove forest, secondary mangrove forest, primary swamp forest, secondary swamp forest, plantation forest, estate crop, pure dry agriculture, dry shrub, wet shrub, mixed dry agriculture, savanna and grasses, paddy field, open swamp, fish pond/aquaculture, transmigration areas, settlement areas, port and harbor, mining areas, bare ground, open water and cloud and no-data [4]. The maps used as main data in Indonesia's National Forest Monitoring System (NFMS) which is also supported by the establishment of Indonesia's National Carbon Accounting System (INCAS) from 2009 [9]. The 23-classes are also used for measuring the occurrence of Land Use, Land Use Change And Forestry (LULUCF) nationally (referred to as wall-to-wall mapping) at a scale of 1:250,000 [10].

However, both existing methods used to support the NFMS are based on information obtained at a national scale and processed using Landsat series imagery with a moderate 80 to $30 \mathrm{~m}$ spatial resolution. This broad-scale national data can lack important detailed information on land cover, forest type and extent by aggregating complex landscapes into homogeneous classes and difficult in order to take account to derive the emission factor for individual bio-regions in term of carbon accounting from deforestation and forest degradation.

Recently, the Indonesia government has invested in upgrading ground stations to receive SPOT-6/7 image data. SPOT-6/7 imagery has the potential to improve land cover mapping results through Object-Based Image Analysis (OBIA) of high-resolution spatial imagery. This because higher resolution imagery such as SPOT-6 imagery has high heterogeneity where the pixel size is smaller than the actual size of the objects.

OBIA method enables pixels to be grouped as objects where their identification is revealed not only by spectral differentiation but also by their shape, texture and spatial continuity [11], [12], [13]. OBIA attempts to translate the manual visual interpretation key approach into a digital automated approach.

Researchers had used OBIA for landcover classification, for example, Govedarica et al. [14] mapped the forests and vineyards in Fruska Gora using RapidEye and WorldView-2 imagery to improve the accuracy and obtained information of thinner vine rows. While Förster \& Kleinschmit [15] mapping forest types, habitats and species conservation using QuickBird imagery and ancillary data such as LiDAR, along with soil, hydrology, forest sitemaps and silvicultural maps at a scale of 1: 5,000 to mapped the detailed distribution of Beech, which was divided into two age classes, Black Alder, Larch, and two age classes of Spruce and Sycamore, including forest clearance and afforestation to a single tree/small group tree level.

This study aimed to investigate the use of OBIA of SPOT-6 imagery with the intent of developing a land cover map of Nagan Raya by expected to produce information at scale 1:25,000 that will improve classification accuracy than those developed using conventional visual and spectral- based methods in order to support of the Indonesian national forest monitoring system. This study processed the classification using ERDAS Imagine Objective (EIO).

\section{MATERIAL AND METHOD}

\section{A. Data}

The study area is located in the two villages of Darul Makmur and Tripa Makmur in Nagan Raya, Aceh Province which situated at $3^{\circ} 43^{\prime} 21.73^{\prime \prime}$ to $4^{\circ} 11^{\prime} 0.5^{\prime \prime}$ North and $96^{\circ} 34^{\prime} 37.0^{\prime \prime}$ to $96^{\circ} 45^{\prime} 7.64^{\prime \prime}$ East. The topography of the villages ranges between 0 and $1,716 \mathrm{~m}$ in elevation with the majority of flat terrain located in the southern region. Deforestation is of concern in the study area evidenced by vast forest changes such as peat swamp forest that decreased by 48,000 ha over two decades between 1990 and 2009. The fastest deforestation occurred during the period 2005-2009 at an estimated rate of 4,000 ha per year. This was primarily due to the expansion of palm oil plantations [16].

The SPOT-6 satellite was used as the primary data source to capture the full extent of the area and perform the OBIA which require 3 scenes of mosaic adjacent images. The data was obtained from the Indonesian ground station, at Parepare, South Sulawesi with the level product is standard ortho. The detail spectral specification of SPOT-6 where a maximum revisit time is 26 days, the wavelength and resolution are as follows;

TABLE I

SPOT-6 WAVELENGTH AND RESOLUTION

\begin{tabular}{|l|l|l|}
\hline Bands & Wavelength Range & Resolution \\
\hline Blue & $0.455 \mu \mathrm{m}-0.525 \mu \mathrm{m}$ & 6 meters \\
\hline Green & $0.530 \mu \mathrm{m}-0.590 \mu \mathrm{m}$ & 6 meters \\
\hline Red & $0.625 \mu \mathrm{m}-0.695 \mu \mathrm{m}$ & 6 meters \\
\hline Near Infrared & $0.760 \mu \mathrm{m}-0.890 \mu \mathrm{m}$ & 6 meters \\
\hline Panchromatic & $0.450 \mu \mathrm{m}-0.745 \mu \mathrm{m}$ & 1.5 meters \\
\hline Source: $[17]$
\end{tabular}

The secondary data were the Shuttle Radar Topography Mission (SRTM), Aceh land cover classification, maps from 2009 in which were validated in the field by the MoFor in some area and a time series imagery from Google Earth.

\section{B. Methods}

1) Image Pre-processing: The images were systematicgeometrically corrected using UTM zone 47 with a projection of WGS 1984 Datum, but a radiometrically correction needs to be processed. A Top of Atmosphere and Bidirectional Reflectance Distribution Function (TOA BRDF) were applied to the images following the pansharpening process.

Pansharpening is used to gain a higher spatial resolution image using the panchromatic image information while attempting to 'preserve' the spectral information of the multispectral data. Some transformations do this better than others where the objective is to maintain either colour balance, for visual interpretation, or spectral integrity for image analysis. The transformations were conducted using Erdas Imagine software version 15, 2015, using Brovey and 
Ehlers Pansharpening. These were objectively evaluated for their suitability in the OBIA process where pansharpening the techniques chosen after initial investigations of several pansharpening techniques that show considerable colour artefacts or mixing into surrounding pixels, which compromised the 'spatial resolution' of features despite the increase in spatial resolution of each pixel. Ehlers developed a pansharpening method based on combining the intensity, hue and saturation (IHS) method with power spectrum filtering in the Fourier domain, while Brovey pansharpening method is achieved by divided each of the multispectral bands separately to the sum of the multispectral bands before multiplying the result with the panchromatic band [18], [19]. Both pansharpening methods were assessed visually and quantitatively based on the ability of the image to provide a better result in separating the objects.

The images also processed for cloud masking which important to be conducted for digital classification. The cloud masking was processed using manual digitisation

2) Feature Separability Using Jeffries-Matusita: The Jeffries-Matusita (JM) method was required to investigate and assessed variation of the object that could be classes. The JM measures the feature separability between any two classes based on Bhattacharyya distance measurement that assumes all classes are Gaussian and that their means and covariance matrices are available. The algorithm uses the JM distance to measure the maximum probabilistic distribution of feature separability where the certain value of separated classes was identified as more than 1.5, while the lower value will be analyzed in order to improve the result. The Jeffries-Matusita (JM) value ranges from $0-2$ [20]. The JM was also used to evaluate the Ehlers and Brovey pansharpening.

3) Training Samples: The initial step in the training samples process was to determine the number of land cover types within the study area for training sample development and subsequent OBIA classification. In order to determine the number of land cover types to be identified and sampled, multiple data sources were used including the existing 2009 MoFor land cover map, vegetation characteristics/classification in Sumatra conducted by Laumonier [21] and visual analysis of the SPOT-6 and Google Earth imagery.

4) Stratification Boundary: Stratification boundary was used to improve the quality in separating the object based on the JM result. This also made based on analyzing from ancillary data such as land cover maps and characteristics of vegetation in Aceh particularly and in Sumatra, generally. Identify the characteristic of vegetation types and physiography of Sumatra was based on the research from Laumonier [21]. One of the methods is divided the vegetation types based on the elevation. In this research, the stratification boundary was determined by several data. They are DEM elevation maps, reference of landcover maps from Ministry of Environment and Forestry (MoEF) and images series from Google Earth.
TABLE II

Altitudinal ZONATION OF VEGETATION IN SUMATRA

\begin{tabular}{|l|l|}
\hline Altitude & Zonation \\
\hline $0-150 \mathrm{~m}$ & Lowlands \\
\hline $150-400 / 500 \mathrm{~m}$ & Low elevation hills \\
\hline $400 / 500-800 / 900 \mathrm{~m}$ & Medium elevation hills \\
\hline $800 / 900-1300 / 1400 \mathrm{~m}$ & Submontane \\
\hline $1300 / 1400-1800 / 1900 \mathrm{~m}$ & Lower montane \\
\hline $1800 / 1900-2400 / 2500 \mathrm{~m}$ & Montane \\
\hline$>2500 \mathrm{~m}$ & $\begin{array}{l}\text { Tropical upper montane and } \\
\text { subalpine }\end{array}$ \\
\hline
\end{tabular}

Source: [21]

5) OBIA Classification: Erdas Imagine Objective (Objectives, version 15) as the main software in this study to process the classification that divided into two steps; pixel image segmentation and object vector classification. Pixel Image Segmentation is a process that first partitions the input image into segments based on similar spectral and spatial characteristics. The object vector classification partitioned segments (raster objects) which developed from the first stage that are assessed using various similarity measurements, such as the geometry of area, perimeter and rectangularity; texture analysis using variance and skewness; and spectral analysis.

The first step of OBIA process which aims to determine the method by segmented the images. In the study, the Single Feature Probability (SFP) and Normalized Difference Vegetation Index (NDVI) were chosen. The SFP used to compute a probability metric images that work based on Multi-Bayesian network pixel on spectral based classifier based on the training sample. While NDVI as a vegetation index computes using band Near-Infrared and Red. The NDVI was used to detect a subtle segmentation class that potential the relatively similar adjacent classes. The metrics were then segmented using Segmentation Lambda Schedule (SLS) based on region growing segmentation, where depending on the characteristic of the object. The segmentation of SLS was determined by a cues weight of spectral (tone), texture, shape, and size. All pixels that have a similar probability value were grouped into the same raster segmentation region. At this process, the Pixel Segment Ratio (PSR) was used to determine the average number of pixels in each segment. The PSR and cue weights were found to play a key role in determining the number of pixels grouped into a single segmentation.

The second step is the object vector classification which grouped the segmented vector and re-classes based on many parameters such as area, shape and Empirical Distribution Analysis (EDA) metric. This study uses EDA that grouped objects based on the similarity of the distribution of object pixels to the distribution of pixels in the representative training sample. The EDA works by comparing the relative frequency of the distribution of pixels as a histogram for both the object and the training sample.

The sequences process in OBIA were applied in each stratification boundary with different weight based on each characteristic of the area. 
6) Accuracy Assessment: The classification result of OBIA was then compared to the classification from a solely spectral based classification Maximum Likelihood (MLC) classifier. There were 623 validation points randomly distributed over the study area for assessing classification accuracy measured using confusion matrix which allows for an overall accuracy of land cover classes, assessed against ground-truth reference data and Kappa analysis [22]. The overall accuracy is defined as the sum of all correctly classified pixels divided by the total number of sample pixels. The User's accuracy corresponds to errors of commission and is used to inform the user (consumer) of the reliability of the classifier; that of the areas classified as a specific land cover type, a certain percentage are actually correct. Conversely, the Producer's accuracy corresponds to errors of omission and is used to inform the analyst (producer) of the performance of the classifier; that the number of correctly classified areas in a particular category is expressed as a percentage of the total number of areas actually belonging to that land cover type.

The Kappa statistic is defined as the ratio of the difference between observed accuracy (defined by the diagonal) and chance agreement (off-diagonals: the sum of the product of row and column totals) and that of the one-chance agreement. The resulting Kappa statistic (coefficient of agreement) yields values between 0 and 1 where a value close to 1 indicates a very strong agreement between the classification and the reference data, and a Kappa statistic close to 0 indicates a poor classification where the results are no better than the random agreement between the reference and the classified pixels.

\section{RESULT AND DISCUSSION}

The quality of the classification depends on the quality of the images as the main input. The pansharpening image was selected based on a comparison between Ehlers and Brovey method. The result showed that Ehlers provide a slightly better in quantitatively separating the object, but lower quality in detail spatial assessment compared to the Brovey (Fig. 1). However, in the OBIA classification, the method also requires a high spatial accuracy. Therefore, the Brovey was chosen as the input base-image to the OBIA process

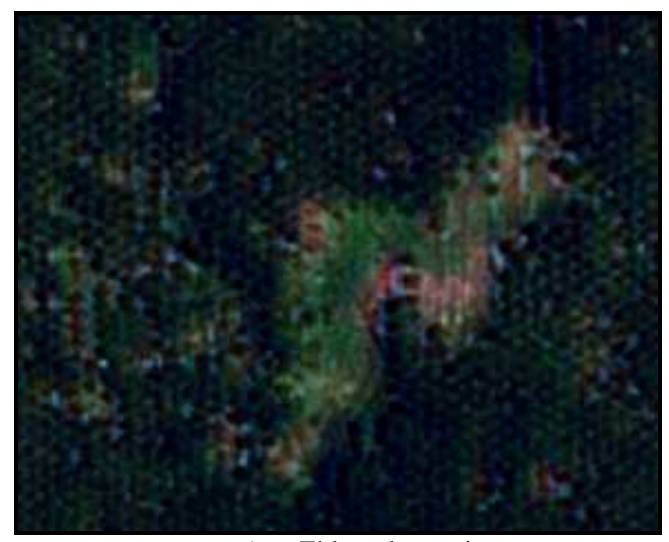

a) Ehlers sharpening

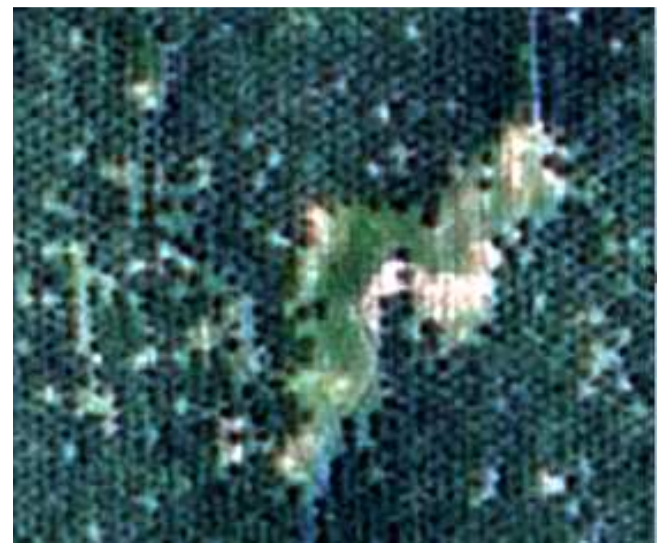

b) Brovey sharpening

Fig. 1 Spatial enhancement between Ehlers and Brovey

Based on the analysis of the area, there were generally 4 groups of vegetation; they are forest, agriculture, plantation and wetland vegetation. Based on the vegetation and physiology of Sumatra, the research found that the area in the southern region was mostly dominated by wetland vegetation/peatland forest, wherein the higher altitude was dominated by dryland forest. Vegetation in the middle altitude was dominated by plantation estate in the east and dryland agriculture in the west. Those zones were segmented using PSR 1000. This because the PSR in the EIO influenced all the classes, and depend on the cue weight parameter in each zone. The values of cue weight were based on several experiments. The cue weight for each zone are as follows;

TABLE III

The Relative Weight Cues Used In the Pixel SEgmentation Process FOR EACH STRATIFICATION ZONE

\begin{tabular}{|l|l|l|l|l|}
\hline Zone & Spectral & Texture & Size & Shape \\
\hline Forest & 0.80 & 0.50 & 0.10 & 0.10 \\
\hline Plantation & 0.80 & 0.50 & 0.20 & 0.20 \\
\hline Agriculture & 0.80 & 0.80 & 0.20 & 0.20 \\
\hline Wetland & 0.80 & 0.50 & 0.20 & 0.20 \\
\hline
\end{tabular}

Source: data analysis.

Based on Table 3, the lower cue weight on size and shape in the forest zone due to relative homogeneity of the object, while to detect small texture of objects in an agriculture zone, the suitable cue weight for texture were highest which was 0.80 compared to other zones.

The OBIA classification in the area resulted in the improvement of the detail classes such as the ability to differentiate between mature and young palm oil plantation in plantation zone based on texture, size, shape, and NDVI. The other detail classification such road, settlement, ponds, land clearing, dry agriculture and mixed agriculture detected in this OBIA method. The classification map is shown in Fig. 2 . 


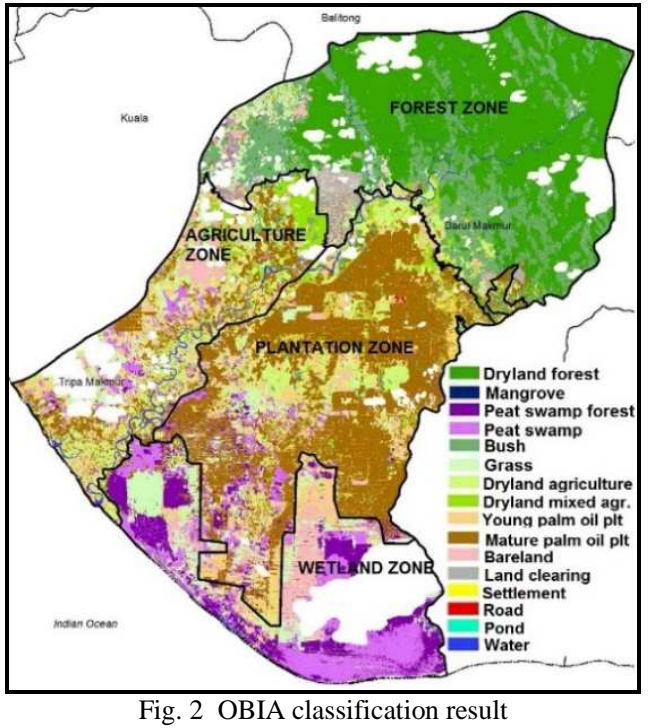

Assessment of the classification accuracy showed that the OBIA's overall accuracy was $83 \%$ with Kappa at 0.82 , while MLC's overall accuracy was at $67 \%$ with Kappa at 0.65 . The producer's accuracy of dryland forest compared between OBIA and MLC were $91 \%$ and $76 \%$, respectively. While producer's accuracy of mature palm oil plantation compared between OBIA and MLC were $92 \%$ and $73 \%$ respectively.

Evaluating the result, the OBIA classification provides a better accuracy than the solely spectral-based classification. This because it removes the salt and paper result. Moreover, the inclusion of the NDVI metric layer will group the similarity vegetation in the variation of vegetation index values exist for a single class, which helps to prove a uniform classification.
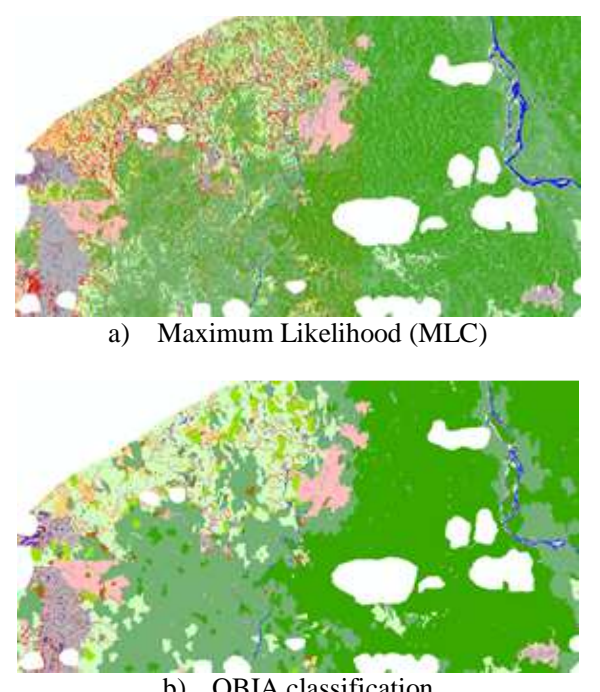

b) OBIA classification

Fig. 3 Sample comparison of landcover classification between MLC and OBIA classification in the forest zone

Thus, detail classification using SPOT-6 imagery has improved the accuracy of land cover classes in order to support the NFMS by enabling the production of accurate land cover and forest extent maps delivered at a regional scale of $1: 25,000$.

\section{CONCLUSIONS}

The OBIA method improved classification which detects objects based on several parameters such as texture, spectral, size, and shape. The method removed the salt and paper classification that occurred in the high spatial resolution imagery which solely classifies using the spectral-based method. The classification uses the Erdas Imagine Objective software to classify the object which segmented the image based on two sequences process; pixel image segmentation and object vector classification.

The OBIA method was improved detail land cover classification to support NFMS at a regional scale 1:25,000 using SPOT-6 imagery. The detail classes that could be detected such as types of the plantation (mature and young palm oil plantation), and land clearing. Moreover, improving the classification in the OBIA method could be achieved by providing the stratification boundary that optimized the cue weight which depends on the characteristic of the area.

\section{ACKNOWLEDGEMENTS}

The author would like to thank Cecile Cutler, Andrew Millington, David Bruce, Erna Sri Adiningsih, Kustiyo and Katmoko Ari, including to all the team members in the image processing division at LAPAN. This research was a part of the author's study at The Flinders University funded by the Australian Award Scholarships.

\section{REFERENCES}

[1] Keenan, R. J., Reams, G. A., Achard, F., de Freitas, J. V., Grainger, A., \& Lindquist, E, Dynamics of global forest area: results from the FAO global forest resources assessment 2015, Forest Ecology and Management, 352, 9-20, 2015.

[2] FAO, Assessment of Forests and Carbon Stocks, 1990-2015. Reduced Overall Emissions, but Increased Degradation, 2015. [ONLINE] Available at http://www.fao.org/. [Accessed 3 June 2016].

[3] Rainforest Action Network, Indonesia's Rainforests: Biodiversity and Endangered Species, 2016. [ONLINE] Available at http://www.ran.org/indonesia_s_rainforests_biodiversity_and_endang ered_species. [Accessed 6 June 2016].

[4] MoEF - Ministry of Environment and Forestry, National Forest Reference Emission Level for Deforestation and Forest Degradation: In the Context of Decision 1/CP.16 para 70 UNFCCC (Encourages developing country Parties to contribute to mitigation actions in the forest sector), 2015.

[5] FAO, Brief on National Forest Inventory (NFI) in Indonesia, 2007. [ONLINE] Available at http://www.fao.org/docrep/016/ap186e/ap186e.pdf. [Accessed 25 May 2016].

[6] MoFor - Ministry of Forestry, Regulation of The Ministry of Forestry No. P.67/Menhut-II/2006: Standards and Criteria Of Forest Inventory. Jakarta, 2006.

[7] Millington, A., Blumler, M., \& Schickhoff, U, The SAGE handbook of biogeography: Sage, 2011.

[8] Soedarto YW, Hanum L, Lestari MS. Analysis and Identification of Landuse on the Coastal Environment of South Sumatra using GIS. International Journal on Advanced Science, Engineering and Information Technology. 2017;7(3)

[9] Roswintiarti, O., Tjahyaningsih, A., Furby, S., \& Wallace, J. M, Indonesia's National Carbon Accounting remote sensing program-A national system for monitoring forest changes. Paper presented at the Geoscience and Remote Sensing Symposium (IGARSS), 2013 IEEE International.

[10] Law of Indonesian National Standard/SNI No. 7645:2010, Land cover classification, 2010. 
[11] Baatz, M., Hoffmann, C., \& Willhauck, G., Progressing from objectbased to object-oriented image analysis; Object-Based Image Analysis (pp. 29-42): Springer, 2008.

[12] Blaschke, T, Object based image analysis for remote sensing. ISPRS Journal of Photogrammetry and Remote Sensing, 65(1), 2-16, 2010.

[13] Navulur, K, Multispectral image analysis using the object-oriented paradigm: CRC press, 2006.

[14] Govedarica, M., Ristic, A., Jovanovic, D., Herbei, M. V., \& Sala, F., Object Oriented Image Analysis in Remote Sensing of Forest and Vineyard Areas. Bulletin of University of Agricultural Sciences and Veterinary Medicine Cluj-Napoca. Horticulture, 72(2), 362-370, 2015.

[15] Förster, M., \& Kleinschmit, B., Object-based classification of QuickBird data using ancillary information for the detection of forest types and NATURA 2000 habitats. Object-based image analysis (pp. 275-290): Springer, 2008.

[16] Widayati, T. H., Rahayu S, and Said Z., Conversions of Tripa peat swamp forest and the consequences on the loss of Sumatran Orangutan (Pongo abelii) habitat and on aboveground $\mathrm{CO} 2$ emissions. Bogor, Indonesia: World Agroforestry Centre (ICRAF), Southeast Asia Regional Program, 2012.

[17] AIRBUS Defence \& Space, SPOT-6 \& SPOT-7 Imagery User Guide, 2013. [ONLINE] Available at http://www.intelligenceairbusds.com/en/4594-spot-67-products. [Accessed 10 August 2015].

[18] Vrabel, J., Multispectral imagery band sharpening study. Photogrammetric engineering and remote sensing, 62(9), 1075-1084, 1996.

[19] Ehlers, M., Beyond Pansharpening: Advances in Data Fusion for Very High Resolution Remote Sensing Data, Proceedings, ISPRS Workshop 'High-Resolution Earth Imaging for Geospatial Information. Paper presented at the Salzburg University, Austria, 2005.

[20] Jensen, J. R., Introductory digital image processing: A remote sensing perspective: Prentice Hall Inc., 1996.

[21] Laumonier, Y., The Vegetation and Physiography of Sumatra: Maps (Vol. 22): Springer Science \& Business Media, 2012.

[22] Congalton, R. G., \& Green, K., Assessing the accuracy of remotely sensed data: principles and practices: CRC press, 2008. 